\title{
PURIFICATION AND PELLETIZATION OF SULFUR FOR NEUTRON DOSIMETRY
}

AUTHORS:

R. D. Rivers

C. A. Kienberger

\section{UNION \\ UNION CARBIDE CORPORATION} CARBIDE NUCLEAR DIVISION

Operating the

OAK RIDGE GASEOUS DIFFUSION PLANT • OAK RIDGE NATIONAL LABORATORY

OAK RIDGE Y-12 PLANT

- PADUCAH gaSEOUS DIFFUSION PLANT 


\section{DISCLAIMER}

This report was prepared as an account of work sponsored by an agency of the United States Government. Neither the United States Government nor any agency Thereof, nor any of their employees, makes any warranty, express or implied, or assumes any legal liability or responsibility for the accuracy, completeness, or usefulness of any information, apparatus, product, or process disclosed, or represents that its use would not infringe privately owned rights. Reference herein to any specific commercial product, process, or service by trade name, trademark, manufacturer, or otherwise does not necessarily constitute or imply its endorsement, recommendation, or favoring by the United States Government or any agency thereof. The views and opinions of authors expressed herein do not necessarily state or reflect those of the United States Government or any agency thereof. 


\section{DISCLAIMER}

Portions of this document may be illegible in electronic image products. Images are produced from the best available original document. 
Printed in the United States of America. Available from Clearinghouse for Federal Scientific and Technical Information, National Bureau of Standards,

U.S. Department of Commerce, Springfield, Virginia 22151

Price: Printed Copy $\$ 3.00$; Microfiche $\$ 0.65$

\section{LEGAL NOTICE}

This report was prepared as an account of Government sponsored work. Neither the United States, nor the Commission, nor any person acting on behalf of the Commission:

A. Makes any warranty or representation, expressed or implied, with respect to the accuracy, completeness, or usefulness of the information contained in this report, or that the use of any information, apparatus, method, or process disclosed in this report may not infringe privately owned rights; or

B. Assumes any liabilities with respect to the use of, or for damages resulting from the use of any information, apparatus, method, or process disclosed in this report.

As used in the above, "person acting on behalf of the Commission" includes any employee or contractor of the Commission, or employee of such contractor, to the extent that such employee or contractor of the Commission, or employee of such contractor prepares, disseminates, or provides access to, any information pursuant to his employment or contract with the Cammission, or his employment with such contractor. 
Date of Issue: February 1, 1968

Report Number: K-1720

Subject Category: CHEMISTRY

PURT,FICATION AND PEILETIZATION

OF SULFUR FOR NEUTRON DOSIMETRY

R. D. Rivers

C. A. Kienberger

Technical Division

UNION CARBIDE CORPORATION

NUCLEAR DIVISION

Oak Ridge Gaceous Diffusion Plant

Oak Kidge, T'ennessee 


\section{THIS PAGE}

\section{WAS INTENTIONALLY \\ LEFT BLANK}


Report Number: $\mathrm{K}-1720$
Subject Category: CHEMISTRY

Title: PURIFICATION AND PELLETIZATION OF SULFUR FOR NEUTRON DOSIMETRY

Authors: R. D. Rivers and

C. A. Kienberger

\section{$\underline{A} \underline{B} \underline{\mathrm{S}} \underline{\mathrm{T}} \underline{\mathrm{R}} \underline{\mathrm{A}} \underline{\mathrm{C}} \underline{\mathrm{T}}$}

Techniques have been developed for purifying and pelletizing elemental sulfur, for application in neutron detectors for area dosimetry. Purification involves the destruction of organic materials by boiling the sulfur with a small dwourl of magnesium oxide, and distillation of the sulfur to separate it from carbonaceous matter and inorganic impurities. The product contains less than 1 ppm of the common metallic impurities and no detectable (<. I ppm) carbona.conus matter.

A unique hot dispensing system was devised for precise delivery of liquid sulfur for casting of 22 -gram pellets. An automatic syringe system withdraws the molten sulfur from a reservoir and delivers it to Pyrex casting rings positioned on a rotating Teflon cold plate. A hot inert gas, directed over the top surface of the pellets, melts a thin layer of sulfur, forming a smooth uniform surface. The average weight of 20 pellets, selected at random, was $22.000 \mathrm{~g}$ with a standard deviation of $\pm 0.009 \mathrm{~g}$ per pellet.

LEG report was prepared as an accoun NOTICE

A. nor the Commission, an account of Government spon

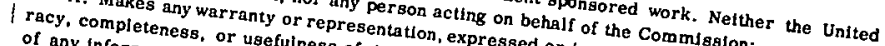
of any informaness. or usefuiness of the inf, expressed or imple commssiton:

privately ouned apparatus, method, loformation contnined in with respect to the acest

B. Assum rights; or

use of any information, appars with respect to the use labed in this report may not infringe

$A s$ used in the above, "por, method, or procese or. or for damages regulung trom

such omploneractor of the cerson acting on behalf of the ed in this report.

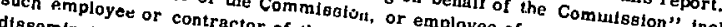

with the Ces, or provides acos the commission, or of such contractor, to thes any em-

with the Commisston, or access to, any informetlon employee of such cont be extent that

with such contraciant to his employment or coares, 


\section{THIS PAGE}

\section{WAS INTENTIONALLY \\ LEFT BLANK}


PURIFICATION AND PELLETIZATION

OF SULFUR FOR NEUTRON DOSIMETRY

CONTENTS

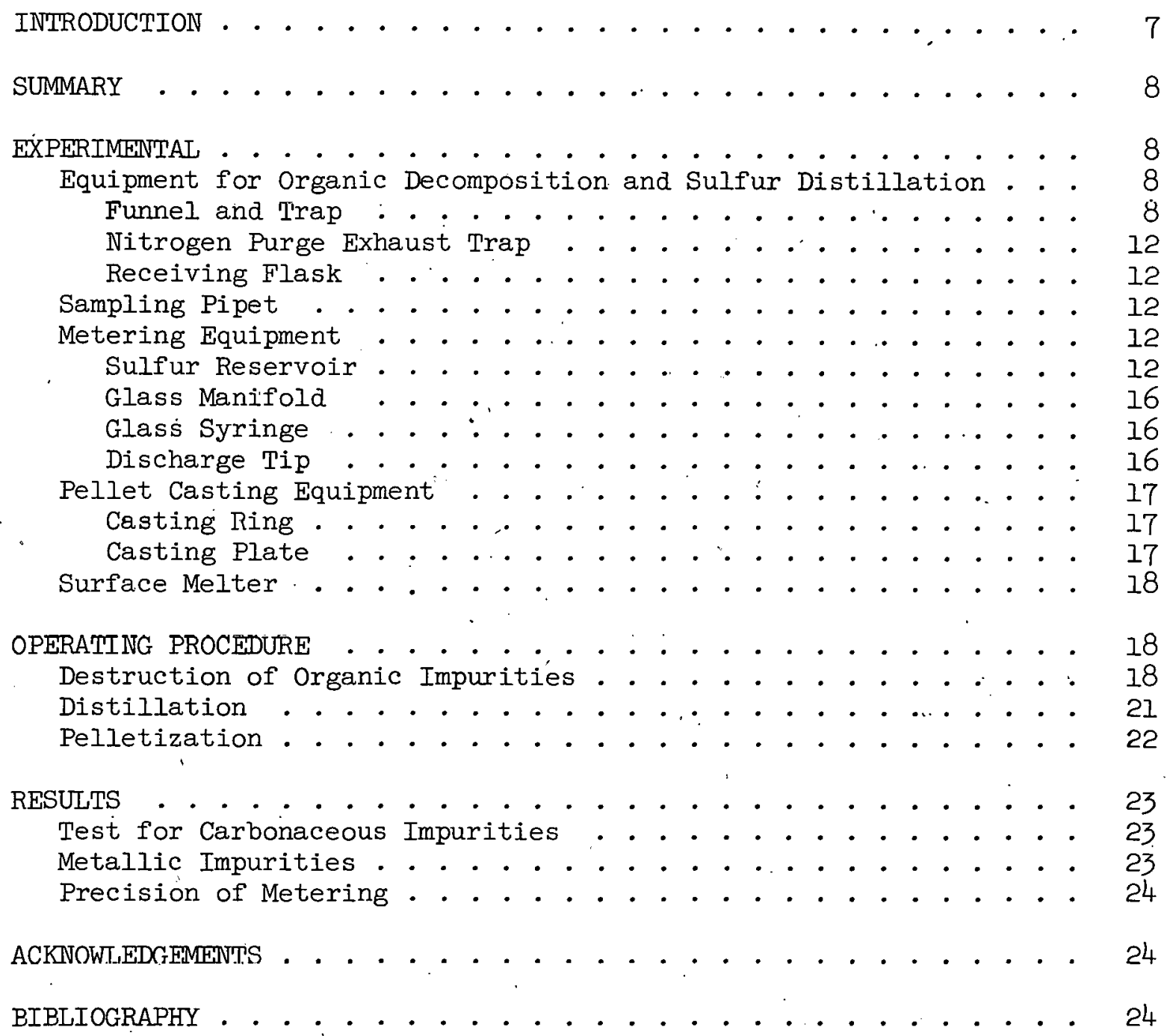


THIS PAGE

\section{WAS INTENTIONALLY LEFT BLANK}


PURIFICATION AND PELLETIZATION

OF SULFUR FOR NEUTRON DOSIMETRY

An economical method was needed for preparing ultra-high purity sulfur and forming it into.precise pellets for use in neutron dosimetry. The sulfur is used for monitoring "fast" neutrons $(3,4)$, by producing the beta radiation of phosphorus -32 generated in the reaction $S^{32}(n, p) P^{32}$. The sulfur must be very pure because most impurities, irradiated with neutrons, produce radioactivity which can interfere in measuring the phosphorus -32 beta activity. To obtain reproducible and accurate measurements of neutron flux by induced beta radiation, the sulfur must be formed into pellets, having precise size, shape, and weight.

The radioactivity due to $\mathrm{P}^{32}$ has generally been measured in the residue after burning the sulfur. Any impurities present in the phosphorus pentoxide, after burning the sulfur, absorb some of the beta activity, decreasing the amount of radiation measured by the counting technique, and introducing imprecision. A more precise, but less sensitive, measurement is the direct determination of surface emission from the pellet. The surface of the sulfur peliet must be smooth and free of voids, for precise and accurate direct counting of the beta radiation.

Aynsley and Robinson ( 1 ) purified sulfur by refluxing it under a dry carbon dioxide blanket for several days. It was then distilled three times in a carbon dioxide atmosphere, with rejection of first and last fractions each time. Two more distillations followed in the presence of nitrogen. Final purification involved five successive fractionations in vacuo, with appropriate rejections.

Bacon and Fanelli (2), in their procedure for separation from organic impurities, melted the sulfur and continued heating slowly until the mass began to foam. When evolution of gas ceased, the temperature was raised to the boiling point, magnesium oxide was added, and boiling continued for 3 to 4 hours. The mixture was allowed to stand at $125^{\circ} \mathrm{C}$. overnight. During this period the black carbonaceous sludge separated, leaving a clear supernatant liquid which was decanted through a filter tube fitted with a plug of Fylex glass wool. Using this filtrate, the preparation was completed in four heating periods at the boiling point, totaling over 100. hours. For each period, one per cent magnesium oxide was added and, together with organic residues, was filtered off before the next heating period was begun.

The above methods for purifying sulfur are involved, time-consuming, and inefficient In the production of ultra-high purity sulfur. A simplified and effective procedure for purifying sulfur was devised and developed, borrowing from these lle thods the two general techniques: destruction of the organic material by boiling with magnesium oxide, and distillation of the sulfur to separate it from impurities. The ultra-pure sulfur product was formed into pellets by metering the molten material and dispensing it into cold Pyrex containing-rings. 
The report describes the procedures and equipment for removing organic impurities, for distillation from inorganic impurities, and for metering and casting the sulfur into uniform pellets. Photographs and schematic diagrams illustrate several pieces of special equipment designed for this work. The purity of sulfur and precision of pellet weight are discussed.

\section{SUMMARY}

Techniques are developed and equipment is devised for purifying and pelletizing elemental sulfur for area neutron dosimetry. The removal of organic impurities is achieved by boiling the sulfur with a small amount of magnesium oxide, and then distilling it. The inorganic impurities are also removed in the distillation. The ultra-pure product is melted and dispensed in a unique all-glass system, delivering to casting rings cooled on a cold Teflon revolving plate. A hot inert gas is impinged on the. pellet surface to obtain a smooth, uniform surface. The purification and handling, through the final pelletization, yields a purity of less than $1 \mathrm{ppm}$ of metallic impurities and no detectable ( $<1 \mathrm{ppm}$ ) carbonaceous impurities. Routine precision of 22 -gram pellets is \pm 0.009 gram with resultant highly reproducible geometry.

\section{EXPERIMEIVTAL}

Equipment for Organic Decomposition and Sulfur Distillation

The destruction of the organic matter and the distillation of the sulfur were conducted in three-liter ruund vullum boiling flaske of Pyrex glass, fitted with nitrogen purge heads, figures 1 and 2 . Nitrogen gas was. supplied through the inlet to the purge head at a flow rate of 250-300 $\mathrm{cc} / \mathrm{min}$, measured with a suitable glass. rotameter and controlled by a small needle valve. The purpose of the nitrogen was to blanket the boiling sulfur to prevent the formation of an explosive mixture of oxygen and sulfur. A mercury seal pressure-release was incorporated into the nitrogen lines to prevent a pressure buildup in the boiling flasks, in the event the purge outlet should become plugged with solidified sulfur. Glas-Col electric heating mantles were used for heating the boiling flasks. The units were mounted on ringstands over a metal tray which was large enough to contain the molten sulfur in case the flasks should break.

Figure 3 shows the two systems. The system on the right was used for boiling the sulfur-magnesium oxide mixture, decomposing the organic material. The sulfur was distilled in the system on the left. The heating mantle for the receiving flask is not shown.

Funnel and Trap. A large funnel (not shown in figure 1), fabricated on a male ground-glass fitting, was used to add powdered sulfur to the boiling flask. Following each stepwise addition of sulfur, the funnel. was removed, replaced with a plug (a sealed male fitting packed with glass wool). This served as a trap which collected and solidified the small amount of sulfur that sublimed during the stepwise additions. After a full $3 \mathrm{~kg}$ charge of sulfur was added, the nitrogen purge attachment (see figure 1) was installed on the boiling flask. 


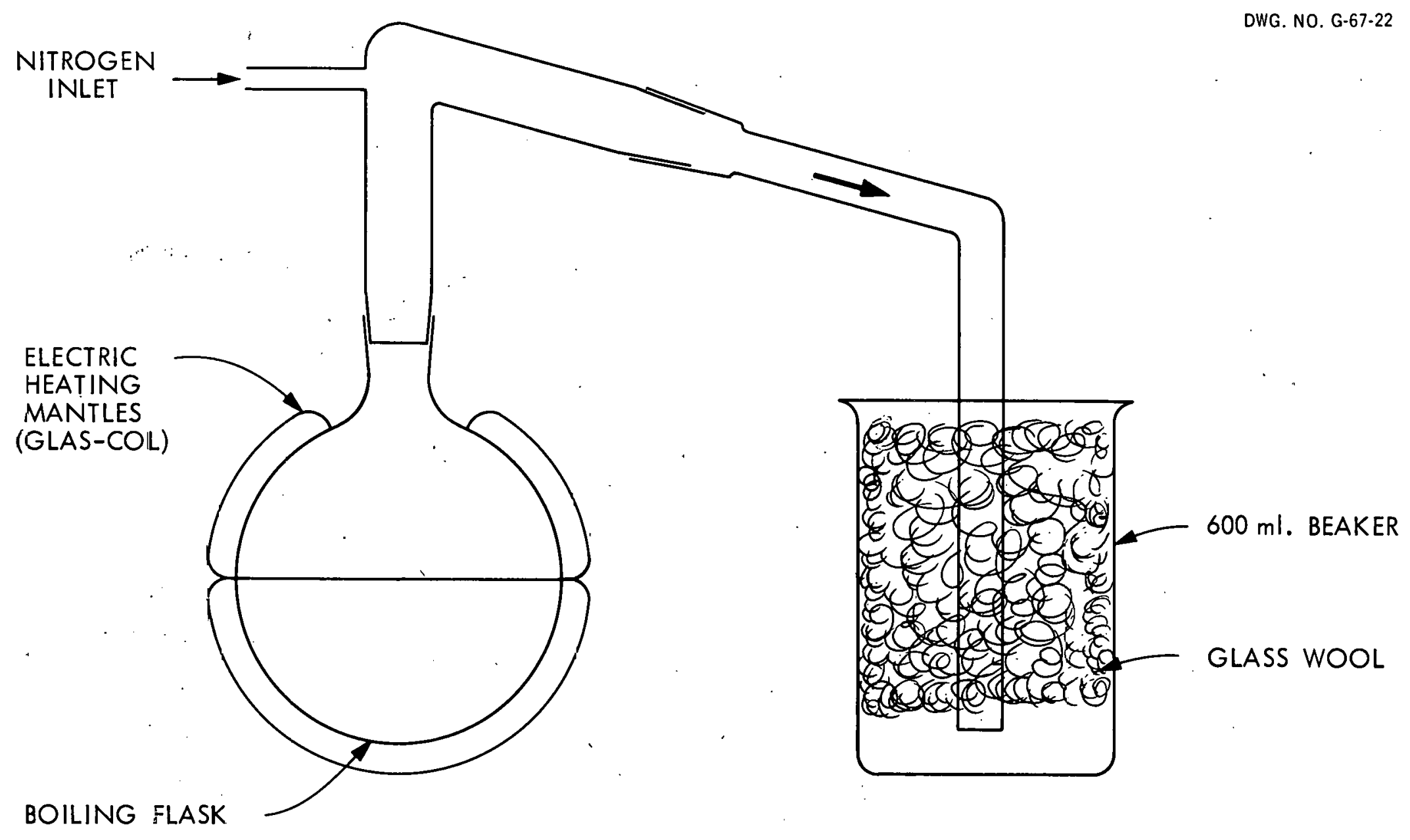

ORGANIC DECOMPOSITION EQUIPMENT

Figure 1 
DWG. NO. G-66-265

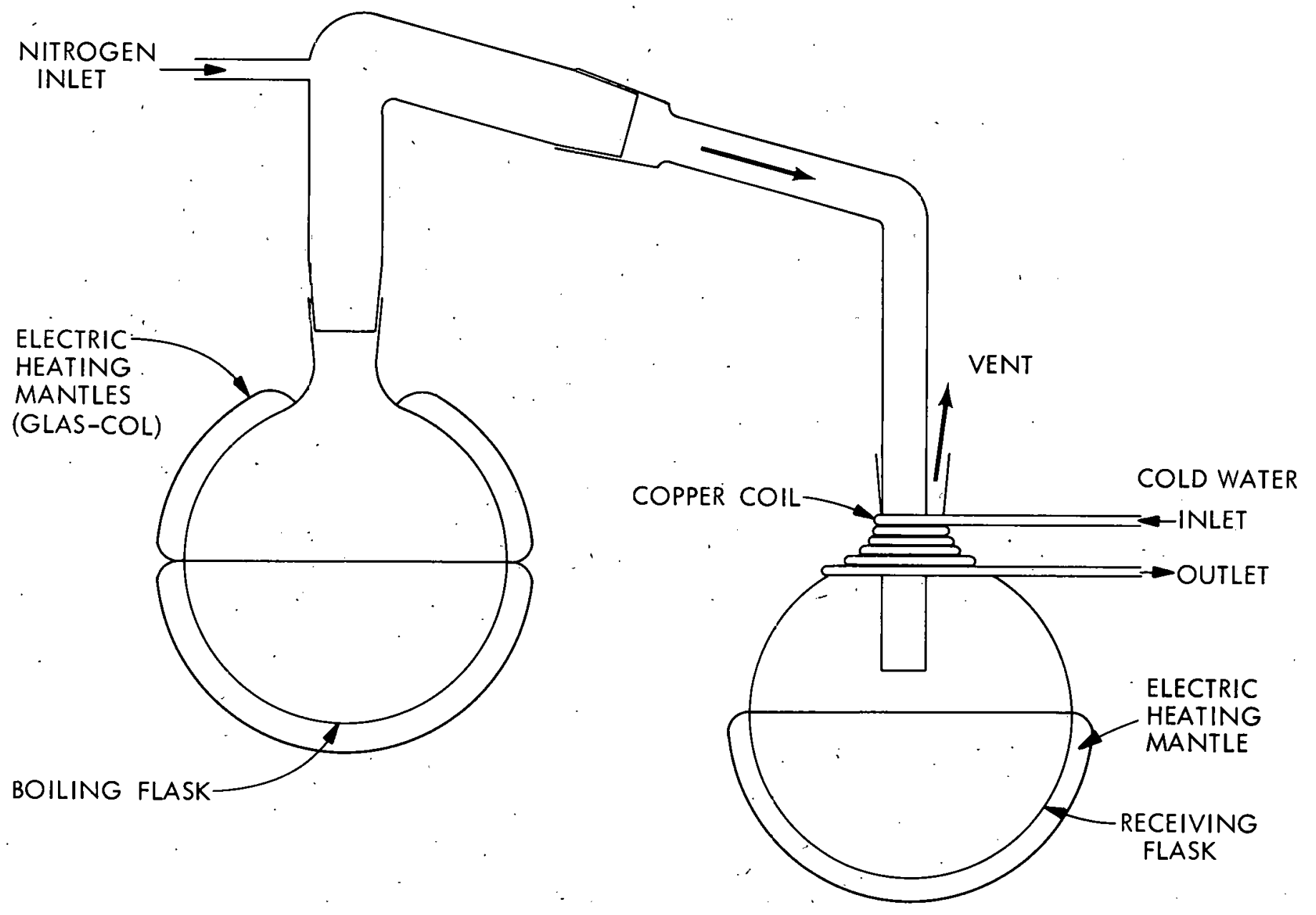

BOILING AND DISTILLING EQUIPMENT

Figure 2 
PHOTO NO. PH-64-580

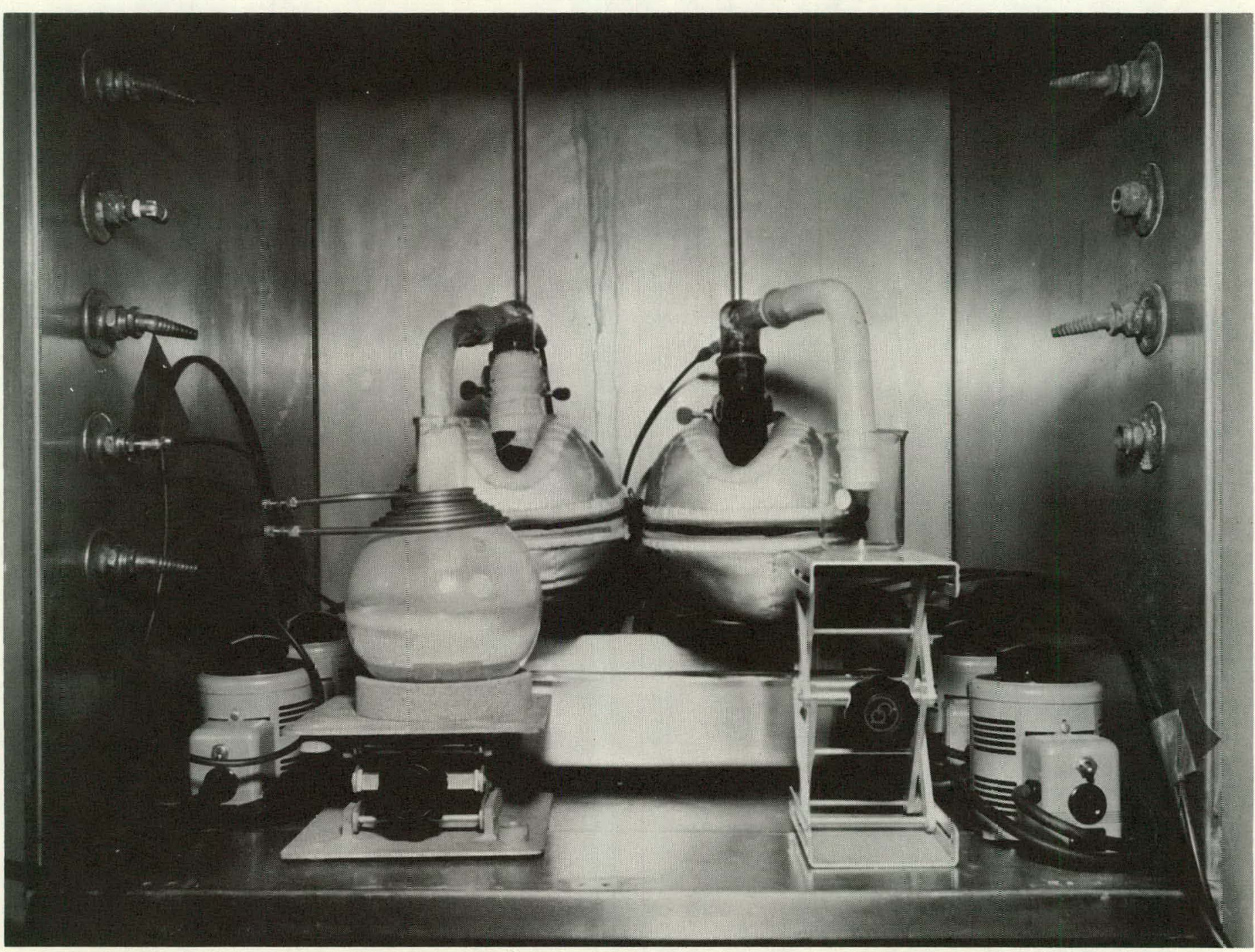

EQUIPMENT =OR ORGANIC DECOMPOSITION AND SULFUR DISTILLATION

Figure 3 
Nitrogen Purge Exhaust Trap. A $600 \mathrm{ml}$ beaker, packed with glass wool, figure 1, served as a trap to collect the sulfur entrained in the nitrogen purge outlet from the organic decomposition flask. The nitrogen purge was exhausted near the bottom of the beaker packed with glass wool.

Receiving Flask. The sulfur was collected from the distillation flask into a three-liter receiving flask, figure 2. A coil made of 1/4 inch copper tubing, and conforming to the spherical shape of the flask, was placed around the neck of the receiving flask; cold water was circulated through it to condense the sublimed sulfur in the flask. The flask was heated with a heating mantle to keep the sulfur molten.

\section{Sampling Pipet}

A $10 \mathrm{ml}$ heated pipet, designed as shown in figure 4, of Pyrex glass with a Teflon stopcock at the top, was employed to take sulfur samples from the three-liter receiving flask. The pipet was heated with an asbestos covered No. 22 nichrome resistance wire, and the temperature was controlled between 120 and $130^{\circ} \mathrm{C}$. with a variable transformer. The sulfur was protected and shielded from the heater wire at the lower end by a glass sleeve which was sealed to the enlarged pipet tip (opening 1/8 inch). The sulfur was drawn into the pipet with a suction bulb; the flow was controlled by the stopcock. The sulfur samples were analyzed for carbonaceous and metallic impurities; it was not necessary to know the exact volume of samples obtained with the heated pipet.

Metering Equipment

A metering device, figurcs 5 and 6 , was designed and fabricated for measuring the ultra-high purity sulfur in the molten state and casting it into pellets of approximately 1.5 inches in diameter and weighing 22.00 grams. It included a temperature-controlled reservoir of molten sulfur, a Pyrex glass manifold, a glass syringe, and a discharge tip. The syringe, glass manifold, and funnel used to fill the reservoir were wrapped with asbestos-covered, No. 22 nichrome wire, and insulated with asbestos. The syringe was operated by a piston-type air cylinder.

Sulfur Reservoir. The reservoir for storing and maintaining the sulfur in the molten state was a two-liter Pyrex bottle placed inside a fourliter asbestos-insulated, stainless steel beaker (see figure 5). The space between the reservoir (bottle) and the beaker was filled with sand to give it heat capacity. The reservoir assembly was placed on a thermoregulated, Mag-Mix stirring hot plate (Thermolyne Corporation, Dubuque, Iowa) which supplied both the controlled heat and agilation for the sulfur in the reservoir. A thermocouple encased in glass was placed in the reservoir to monitor the temperature of the sulfur. A glass funnel was used to supply molten sulfur to the reservoir; when not in use, the funnel was covered with a Teflon cap. The reservoir was also fitted with a Teflon cover fabricated with appropriate ports for the funnel and the glass tubing connecting the manifold. 


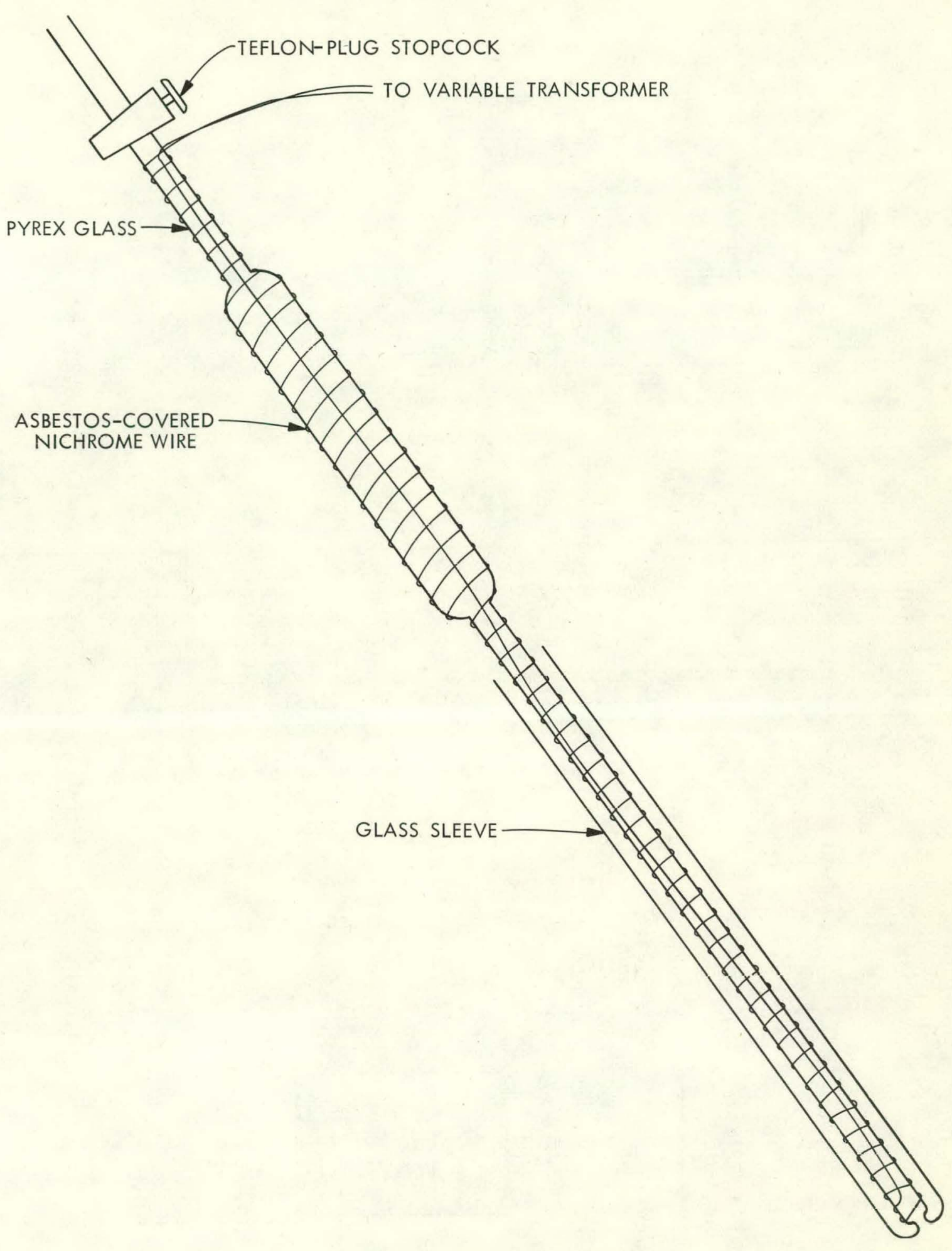

SAMPLING PIPET

Figure 4 


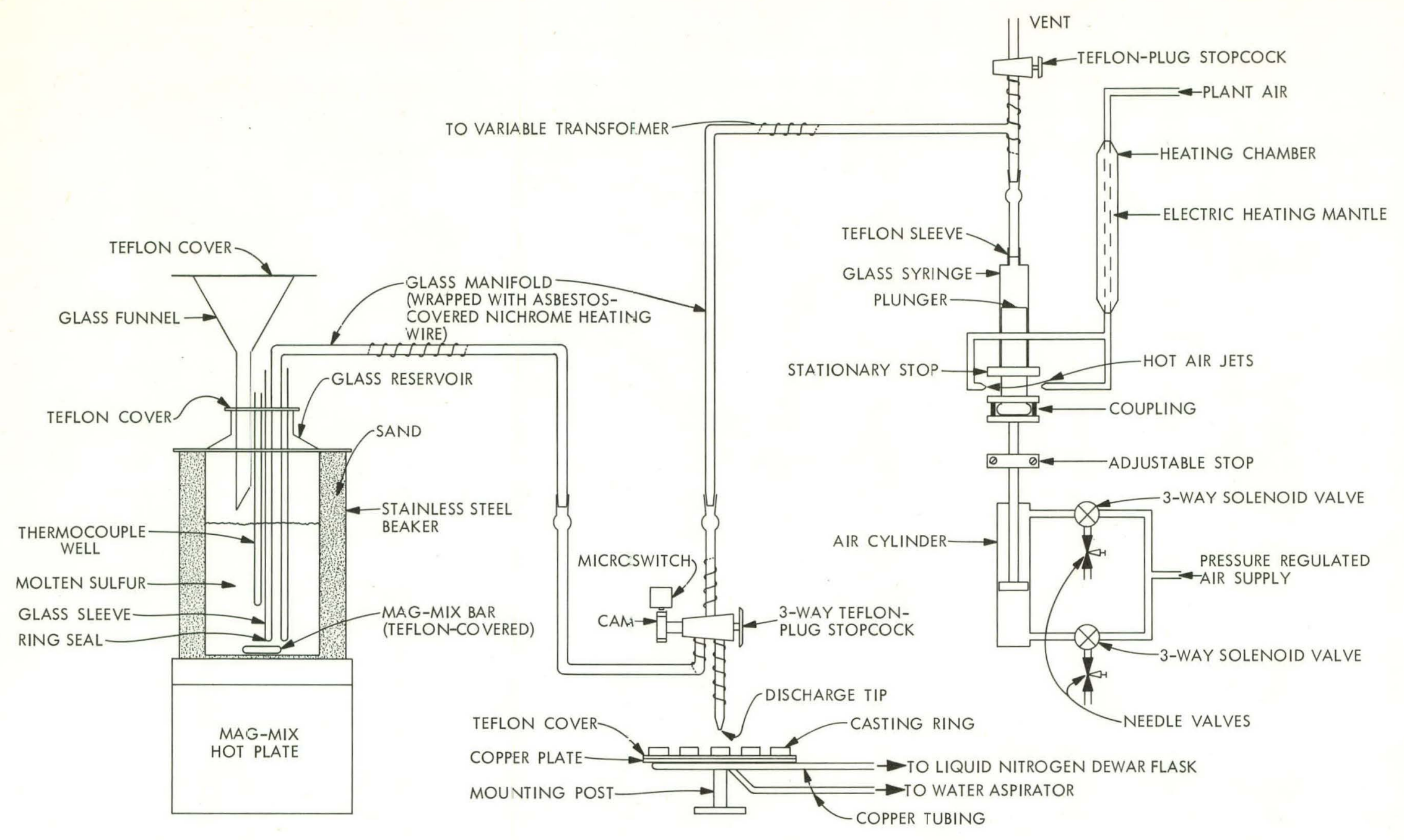

METERING EQUIPMENT AND RESERVOIR FOR MOLTEN SULFUR

Figure 5 
PHOTO NO. PH-64-579

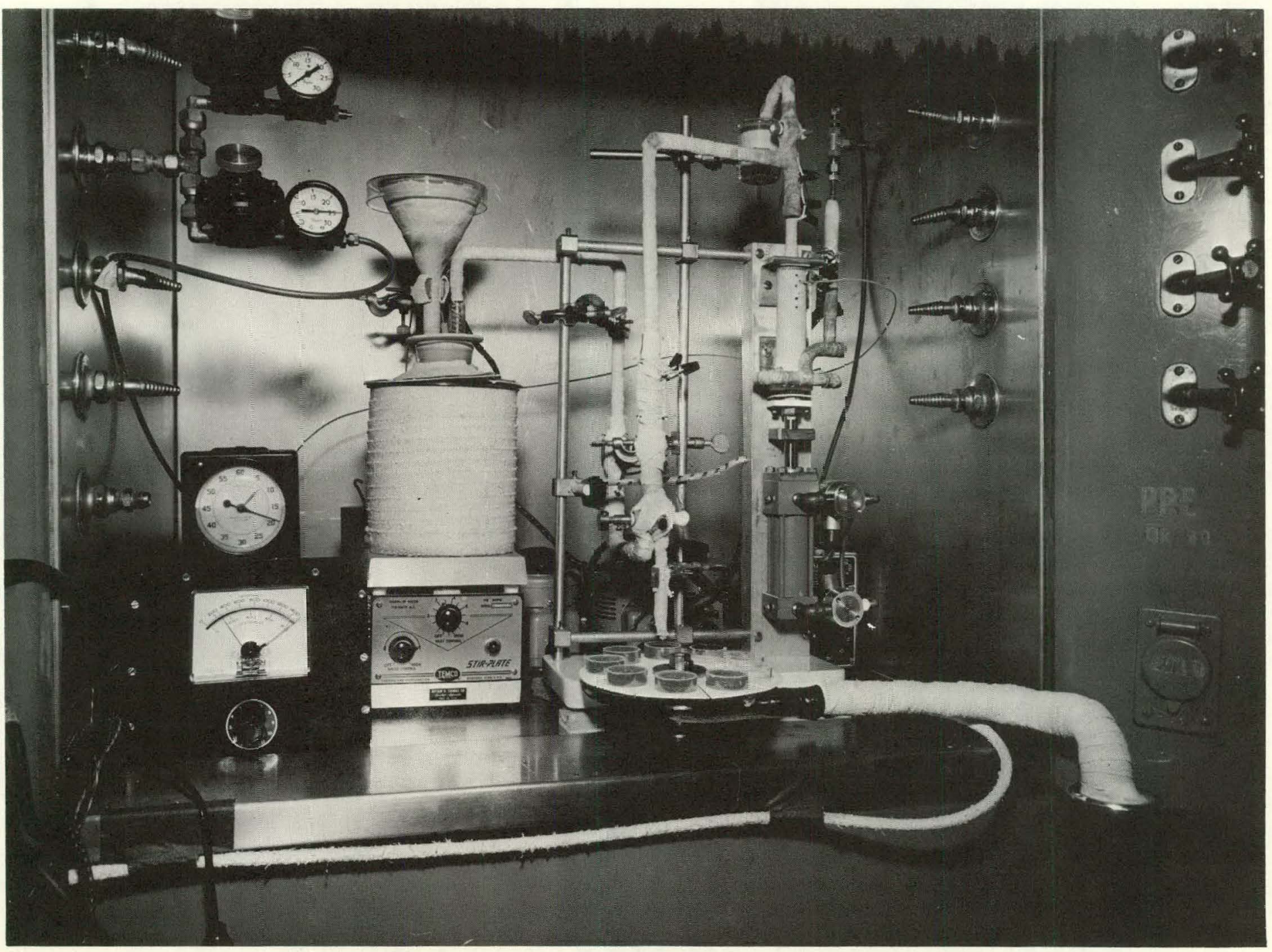

MOLTEN SULFUR RESERVOIR. AND METERING EQUIPMENT

Figure 6 
Glass Manifold. The manifold had a three-way Teflon-plug glass stopcock, through which the molten sulfur from the reservoir was supplied to the syringe and delivered to the discharge-tip, figure 5. A small Teflon-plug glass stopcock was located directly above the syringe; through this stopcock air was expelled during the filling of the system with molten sulfur. The nichrome wire on the manifold extended down into the reservoir on the withdrawal tube and was protected from the molten sulfur with a glass sleeve sealed to the manifold. The nichrome wires were connected to a ll0-volt outlet through a variable transformer which controlled the temperature between 120 and $130^{\circ} \mathrm{C}$. Small openings were made in the asbestos insulation; the temperatures were monitored by placing a small thermocouple into these openings.

Glass Syringe. A $30 \mathrm{ml}$ syringe (Luer) was connected to the manifold by removing the metal tip (Luer-Lok), inverting the syringe, and attaching the glass end to the glass manifold with a Teflon sleeve, figure 5. The plunger of the glass syringe was attached to the piston of the air cylinder (see figures 5 and 6 ). The piston was operated by a control mechanism consisting of two three-way solenoid valves mounted on the two cylinder inlets. The solenoid valves were operated by a single-pole double-throw microswitch mounted over a cam, which was connected directly to the plug of the three-way sulfur-delivery stopcock. The turning of this stopcock activated the microswitch, which energized one solenoid valve, and simultaneously deenergized the other solenoid valve; this moved the piston in the air cylinder and the plunger in the syringe. The system was adjusted so that when the three-way stopcock on the manifold was opened to the sulfur reservoir, the plunger in the syringe was opened by the air piston; and when the stopcock was turned to the discharge position, the cam activated the double-throw microswitch which operated the valves and plunger, forcing the sulfur out of the manitold. The stroke speed of the plunger was controlled with small needle valves (figure 5) mounted in the air cylinder vents (through the solenoid valves). By closing these needle valves, the flow of air was restricted, slowing the movements of the piston in the air cylinder.

The system was adjusted to deliver approximately $22 \mathrm{~g}$ of sulfur at a temperature between 120 and $130^{\circ} \mathrm{C}$. These adjustments were made by positioning the stop-block on the air cylinder ram and by inserting steel shim stock between the movable coupling and the adjustable and stationary stops. A movement of the plunger of only one-thousandth of an inch was equivalent to approximately $20 \mathrm{mg}$ of sulfur.

Two hot air streams, totalling 4 to 5 liters/min, were directed onto the extended portion of the plunger to keep the sulfur from solidifying on it. The air was heated to $150^{\circ} \mathrm{C}$. by passing it through a $3 / 8$ inch copper tubing wrapped with an electric heating element (figures 5 and 6).

Discharge Tip. The discharge tip was connected to the molten sulfur system through the three-way stopcock. The opening in the tip, through which the molten sulfur was discharged into glass casting rings, was approximately $1 \mathrm{~mm}$ in diameter. 
Pellet Casting Equipment

A pellet casting system, shown in figures 5 and 6 , was devised for forming the sulfur into pellets. The system included casting rings and a casting plate.

Casting Ring. The molten sulfur was formed into pellets by delivering fixed quantities (22 g) to the glass casting rings. The rings had an inside diameter of $1.500 \pm 0.005$ inches and were 0.5 inch high. Several dozen rings were fabricated from precision Pyrex tubing with a wall thickness of $3 / 32$ inch. Nine of the rings were used on the casting plate at one time.

The initial rings were made from standard quality Pyrex tubing; they yielded sulfur pellets with excessive variation in diameter. These pellets were unsatisfactory for neutron dosimetry.

Casting Plate. A cold plate covered with Teflon rapidly cooled the molten sulfur so that the pellets were easily contained and removed from the rotating plate, increasing the number of pellets that could be formed in a period of time.

The cold plate was a stationary copper disk, $1 / 4$ inch thick and 8 inches in diameter, with a spiral cooling coil of 1/4 copper tubing soldered to the underneath side. The plate was mounted below the discharge tip of the metering device on a center support rod, $1 / 2$ inch in diameter, which extended up through the plate to serve as an axis on which the Teflon cover rotated. The Teflon cover was rotated on the cold plate by the operator after each sulfur delivery to a casting ring. One end of the copper tubing (containing the cooling coil) was connected to a water aspirator and the other end extended into a Dewar flask of liquid.

nitroger. The aspirator drew liquid nitrogen into the tubing; the nitrogen vaporized before it reached the coil. The cold nitrogen vapors flowed through the copper coil at the rate of 8 to $91 / \mathrm{min}$, cooling the copper plate to about $0^{\circ} \mathrm{C}$.

The original Teflon cover used on the cold plate was a disk, $1 / 8$ inch thick and 8-1/4 inches in diameter, with a $1 / 2$ inch hule in the center for mounting it on the center rod. This cover swelled after repeated use in casting sulfur pellets and needed to be replaced. The swelling caused a slight convex surface under the sulfur pellet, resulting in a slightly concave surface on the bottom side of the pellet. The sulfur tended to adhere to the Teflon surface. The pellet was very easily removed, however, by pushing down on the casting ring, which flexed the Teflon and released the pellet.

An attempt was made to replace the $1 / 8$ inch thick Teflun cover with a 10 mil thick sheet of Teflon, bonded to a $1 / 8$ inch thick aluminum disk with an epoxy resin to provide rigidity for rotating. The resultant pellets were smooth with a level surface on the bottom side, but they were not easily removed from the casting plate. The use of the thicker 
Teflon cover was a better operating technique, replacing it when it swelled excessively.

Surface Melter

The surface melter, figures 7 and 8, produced a smooth level surface on the sulfur pellet by melting the hardened meniscus around the edge of the pellet and the top surface of sulfur to a depth of $1 / 16$ inch. The molten sulfur filled the void spaces left by shrinkage during the original crystallization. The design of the melter was based on two concentric Pyrex glass tubes. Helium (inert gas) was injected at the top of the outer tube and was heated as it flowed down the tube. It flowed across the top of the pellet as it passed into the center tube, figure 7 , and was aspirated out the top of the tube.

The outer tube was wrapped with an asbestos covered nichrome resistance heating wire, powered through a variable transformer. The enlargement at the top of the outer tube received helium from two plastic tubes supplied from the regulator on the cylinder of helium. The opening at the bottom of the outer concentric tube was approximately $1 / 32$ inch smaller than the casting ring, and the outside tube was $1 / 16$ inch longer than the center tube.

The center (exhaust) tube had an enlarged head, figure 7, forming a constricted annulus. This annulus accelerated the linear flow of the hot gas; the shape induced the flow of gas toward the center. An aspirator was employed to exhaust the gases and vapors from the center tube, directing the flow of gas from the outer tube to the center tube. This inward flow of gas also caused the sulfur to flow toward the center, filling void spaces in the center portion and pulling excess sultur Irom the edges. Helium gas was used as the inert gas because of its high thermal conductivity and inertness to sulfur. The center (exhaust) tube was connected at the top with plastic tubing to a charcoal trap and water aspirator. The charcoal trap removed sublimed sulfur vapors.

The surface melter was mounted above a motorized turntable so that a casting ring on the turntable was about $1 / 32$ inch below the melter. The turntable was covered with Teflon which had six depressions for positioning the casting rings containing sulfur (figure 8). A timing and sequencing mechanism moved the table to a new position every 60 seconds and operated a solenoid valve which controlled the flow of helium gas. Gas was fed to the melter only when the casting ring was positioned under it.

\section{OPERATING PROCEDURE}

Destruction of Organic Impurities

Approximately $3 \mathrm{~kg}$ of National Formulation Grade sublimed sulfur and $30 \mathrm{~g}$ of magnesium oxide are weighed for processing. The boiling flask with top and bottom heating mantles around it is set-up as shown in 
DWG. NO. G-66-268

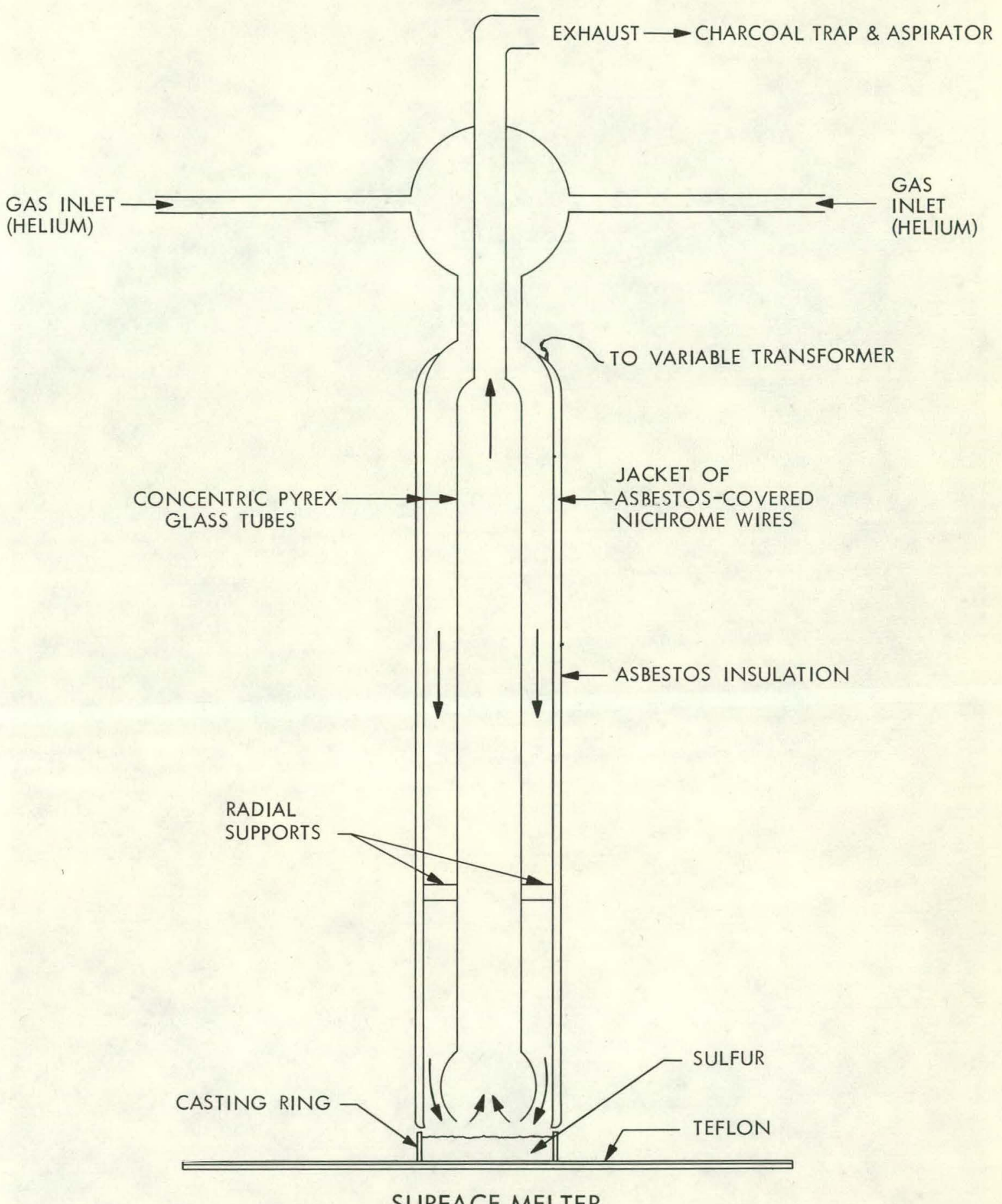

Figure 7 


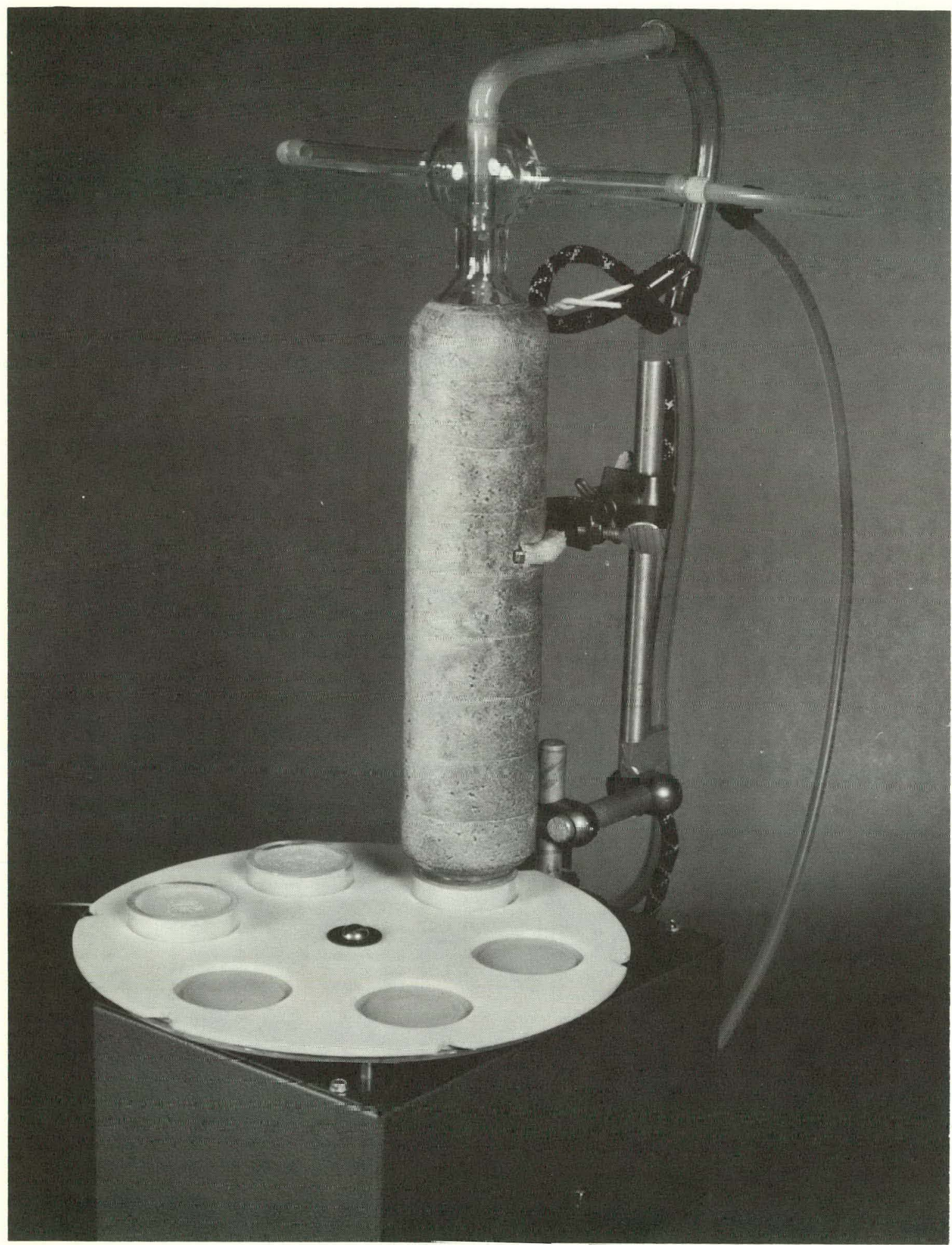

ANNULAR SURFACE MELTER

Figure 8 
figure 1. The top mantle is raised in front so that the contents of the flask are visible during the filling step. The funnel on the male groundglass joint is placed in the three-liter boiling flask and $300 \mathrm{~g}$ (approximate) of sulfur and $30 \mathrm{~g}$ of magnesium oxide are added through the funnel to the boiling flask. The funnel is removed, and the male fitting (packed with glass wool) is inserted in the top of the three-liter boiling flask to prevent sublimed sulfur from leaving the system.

The lower part of the electric heating mantle is turned on; the upper part remains off, to minimize foaming and loss of sulfur during the addition of sulfur. When the sulfur in the flask is almost all melted, a second batch of $300 \mathrm{~g}$ of sulfur is added, as above. The addition of 300-gram batches is repeated every 7 to 10 minutes until approximately $3 \mathrm{~kg}$ of sulfur has been added to the $30 \mathrm{~g}$ of magnesium oxide in the flask.

CAUIION: The temperature of the sulfur at the surface must be kept below the autoignition point $\left(232^{\circ} \mathrm{C}\right.$.) during the filling of the flask. 'l'his is more nearly assured as long as there is some solid sulfur in the boiling flask. (The melting point of, sulfur is $113^{\circ} \mathrm{C}$. )

The nitrogen purge head and line are inserted in the top of the flask, in place of the funnel, and the flow of nitrogen is adjusted to 250 to $300 \mathrm{cr} / \mathrm{min}$. The top heating mantle is lowered and luried on.

When the sulfur starts boiling $\left(444.6^{\circ} \mathrm{C}\right.$.) and the vapors rise to the neck of the flask, the temperature of the upper heating mantle is adjusted so that the sulfur refluxes up to, but not into, the purge outlet tube. The volatilized organic impurities are swept out by the nitrogen purge gas. The sulfur is maintained at this boiling temperature for four hours. The heating mantles are then turned off and the flask and contents are allowed to cool. When the system has cooled for 15 to 20 minutes, the nitrogen purge head with the nitrogen flowing through it is lifted up about 1-1/4 inches and tilted sideways to keep it from falling back into the flask joint. This position keeps the joint from freezing when the sulfur solialfies.

The nitrogen purge head is replaced in the flask with the distillation purge head and the delivery tube, figures 2 and 3 . These heads are identical in design but they are exchanged to prevent contamination of the distillate with volatile impurities that may have condensed in the nitrogen purge head. The sulfur is ready for distillation.

\section{Distillation}

The heating mantles are turned on and the flow of nitrogen is adjusted to 250 to $300 \mathrm{cc} / \mathrm{min}$, figure 2. The receiving flask is positioned so that the outlet of the delivery tube is 1 to 2 inches below the neck of the receiving flask. The power to the heating mantles is adjusted by variable transformers so that the temperature of the sulfur is raised from room temperature to the boiling point in about 1.5 hours. l'he transformers are 
- then regulated to keep the sulfur molten in the distillation head and delivery tube. At the start of the distillation, the delivery tube may have to be 'warmed gently with a torch to promote a steady flow of liquid sulfur into the receiving flask. Samples are removed from the receiving flask for analysis with the heated pipet (figure 4 ) and transferred to a test tube for determining carbonaceous impurities or to a platinum dish for determining nonvolatile and metallic impurities. The receiving flask is heated with the lower part of a heating mantle to keep the sulfur molten. Cooling water is circulated through the coil around the upper part of the receiving flask, to prevent sublimation of the sulfur out of the receiving flask.

The distillation of the sulfur is completed in about 5 hours with a steady distillation rate of about 0.5 to $0.6 \mathrm{~kg} / \mathrm{hr}$. Approximately $250 \mathrm{~g}$ of material remains as tails in the distillation flask.

\section{Pelletization}

The hot plate under the glass reservoir, figures 5 and 6 , is turned on and the temperature is regulated between 120 and $130^{\circ} \mathrm{C}$. The heater around the glass manifold is turned on and the temperature is controlled between 120 and $130^{\circ} \mathrm{C}$. by a variable transformer. Liquid nitrogen is added to the Dewar flask, and the aspirator is turned on to draw the cold nitrogen vapors through the cooling coil under the casting plate.

Molten sulfur is added to the reservoir through the heated funnel. The three-way stopcock is upelled lu lie reacrvoir and the plunger nn the syringe is placed in the "Fill" position, creating a partial vacuum in the manifold. Molten sulfur flows into the manifold and into the syringe. The three-way stopcock is closed, and the stopcock above the syringe is opened as the plunger is moved to the "Empty" position by manually activating the microswitch. This operation purges air out of the system. The stopcock above the syringe is then closed, and the syringe is again filled with sulfur after opening the three-way stopcock to the reservoir. The three-way stopcock is opened to the discharge tip to purge. the air out of the delivery part of the system.

The casting rings are placed on the casting plate, figures 5 and 6 , one being placed directly under the discharge tip of the glass manifold. The three-way stopcock (which operates the single-pole double-throw microswitch) is opened to the reservoir. The microswitch also energizes the solenoid valve which opens the syringe to the "Fill" position. The syringe fills with molten sulfur. The three-way stopcock is then opened to the discharge tip. By cam action on the double-throw microswitch, the solenoids operate the air cylinder and plunger, which forces the molten sulfur out of the syringe, into the casting ring on the cold casting. plate. When the plunger stops ("Empty" position), the three-way stopcock is closed and the casting plate is manually turned about $1 / 9$ of a revolution. The metering operation is repeated with a fairly uniform time cycle. 
After the sulfur pellet cools, the ring containing the pellet is removed from the casting plate and placed on the turntable of the surface melter, figure 8. Helium is fed into the melter at the rate of about 8 liters $/ \mathrm{min}$. The temperature of the heating jacket of the melter is controlled so that the temperature of the gases at the pellet is between 150 and $175^{\circ} \mathrm{C}$., observed periodically by a thermometer. The water aspirator, connected to the center exhaust tube of the melter, is turned on. The motor to the turntable is energized and the casting ring containing the sulfur is positioned under the surface melter and retained for 55 seconds.

The turntable then moves one position and the melted sulfur on the surface of the pellet recrystallizes. The casting ring containing the sulfur is then removed from the turntable, placed on an aluminum foil with others, covered with an aluminum foil, and allowed to stand overnight. The sulfur shrinks and the glass casting ring is easily removed for reuse. The sulfur pellets are handled gently with Teflon-tipped forceps, and finally wrapped in aluminum foil to prevent contamination.

The casting rings and casting plate are cleaned with scouring powder, dipped in chromic acid, rinsed with distilied water, and dried. Any sizeablc deposits of sulfur that adhere to the surface are scraped off with a small spatula prior to cleaning.

\section{RESULTS}

Test for Carbonaceous Impurities

The method described by Bacon and Fanelli (2) is used to determine the amount of carbonaceous impurities present in the sulfur. A test tube is cleaned by boiling in chromic acid, rinsing with distilled water, and air drying. A sulfur sample, about 4 grams, is placed in the tube and slowly heated to boiling. The sulfur is boiled for 2 to 3 minutes, and then allowed to solidify.

The appearance of black spots on the bot.tom of the tube, where it had been in contact with the flame, indicates the presence of carbonaceous impurities. Bacon and Fanelli reported that the black material formed by heating sinffur containing organic matter has, with few. exceptions, been accepted as carbon. They also have reported: that sulfur samples containing about $0.04 \%$ oil completely blackens the bottom of the test tube; that sulfur containing less than 1 ppm of oil, when tested, shows small black spots in it.

Tests of the sulfur samples, purified in the present development, showed no black spots.in them, indicating no detectable carbonaceous impurities a content of well below $1 \mathrm{ppm}$.

Metallic Impurities

Pellets $(22 \mathrm{~g})$ of the purified sulfur were burned in air in platinum dishes. There was no visible residue remaining in the platinum dish 
after the burning of a pellet. The dish was washed with $8 \mathrm{~N}$ nitric acid in the spectrographic laboratory for determination of the common metallic impurities. Less than 1 ppm of any of the common metallic impurities was detected. A:220-gram sample was also ashed and similarly analyzed. Table I shows the metallic content determined spectrographically. Pellets with this purity are suitable for neutron dosimetry.

For comparison, a sample of $22 \mathrm{~g}$ of the purest (99.9999\%, manufacturer claim) commercial sulfur known to the authors was burned in air. The weight of the visible residue was equivalent to $55 \mathrm{ppm}$ of impurities. Spectrographic analysis of the residue showed $7 \mathrm{ppm}$ of detectable metallic impurities in the original sample.

\section{Precision of Metering}

Over 2500 pellets were prepared by metering the molten ultra-pure sulfur into casting rings and smoothing the surface with the annular surface melter'. The average weight of 20 pellets selected at random was 22.000 with a standard deviation of $\pm 0.009 \mathrm{~g}$ per pellet. The uniformity of size of the pellets made it unnecessary to weigh the individual pellets; occasional random samples confirmed weight control.

The surface on both sides of the pellets was fairly smooth and uniform. There were no observed voids in the crystallized sulfur pellets.

\section{ACKNOWLEDG EMENTS}

The authors wish to express their appreciation for the encouragement and suggestions of J.C. Bailey of the Physics Department and C.W. Weber of the Chemical Analysis Department. The spectrographic analyses were performed by D. C. S. Randolph under the supervision of R. B. Farrar. J. W. Williams assisted in the preparation of more than 2500 pellets for use in a multiplant dosimeter installation program.

\section{BIBLIOGRAPHY}

1. Aynsley, E. E., and Robinson, P. I., "Sulfur," Chemistry and Industry, 13, $392(1935)$.

2. Bacon, R. F., and Fanelli, R., "Purification of Sulfur," Industrial and Engineering Chemistry, 34, No. 9, 1043-48 (1942).

3. Hurst, G. S. and Ritchie, R. H., Radiation Accidents: Dosimetric Aspects of Neutron and Gamma Ray Exposures, Union Carbide Corporation, Nuclear Division, Oak Ridge National Laboratory, Oak Ridge, Tennessee, November 2, 1959 (ORNL-2748, Part H).

4. Parker, B. H., The Measurement of Fast Neutron Flux Using the $\mathrm{S}^{32}(\mathrm{n}, \mathrm{p}) \mathrm{P}^{32}$ Reaction, English.Electric Compariy, Harwell, England, Gt. Brit. Atomic Energy, November 1960 (AERE-R 3443) 
TABLE I

METALUIC IMPURITIES IN PURIFIED SULFUR

(Ash Examination)

\begin{tabular}{rl}
\hline Element & \multicolumn{1}{c}{$\begin{array}{c}\text { Concentration, } \\
\text { ppm }\end{array}$} \\
\hline $\mathrm{Ag}$ & $<0.003$ \\
$\mathrm{AI}$ & $<0.02$ \\
$\mathrm{Be}$ & $<0.0007$ \\
$\mathrm{Bi}$ & $<0.006$ \\
$\mathrm{Ca}$ & $<0.07$ \\
$\mathrm{Cd}$ & $<0.02$ \\
$\mathrm{Co}$ & 0.002 \\
$\mathrm{Cr}$ & $<0.0004$ \\
$\mathrm{Cu}$ & $<0.03$ \\
$\mathrm{Fe}$ & $<0.01$ \\
$\mathrm{Mg}$ & $<0.007$ \\
$\mathrm{Mn}$ & $<0.007$ \\
$\mathrm{Mo}$ & $<0.007$ \\
$\mathrm{Ni}$ & $<0.07$ \\
$\mathrm{~Pb}$ & $<0.07$ \\
$\mathrm{Sh}$ & $<0.16$ \\
$\mathrm{Si}$ & $<0.03$ \\
$\mathrm{Sn}$ & $<0.007$ \\
$\mathrm{Ti}$ & $<0.07$ \\
$\mathrm{~V}$ & \\
$\mathrm{Zn}$ & $<$ \\
& $<$ \\
\hline
\end{tabular}

